\title{
The continued use of L-tryptophan in chronic affective disorder
}

\author{
Donald Eccleston
}

The possibility that L-tryptophan would become no longer available as an adjunct to other antidepressant medication in severe affective disorder was discussed recently in these pages (Eccleston, 1993). Since then the Committee for Safety in Medicines (CSM) has extensively and painstakingly reviewed the evidence that the L-tryptophan currently avallable could produce the eosinophilia myalgia syndrome. The potential efficacy of the drug as a combined treatment in affective disorders was considered in parallel. It is with considerable satisfaction that it can now be reported that L-tryptophan will be available to psychiatrists in the future and that the College representatives on the CSM were able to give the perspective of practising clinicians in this particularly difficult area of therapy.

Quite naturally, survelllance of this product will for some time be higher than with other drugs. The CSM have imposed a number of conditions which are given on the data sheet. Essentially, prior supplying of L-tryptophan, the prescriber and patient must be registered with the Optimax Information and Clinical Support (OPTICS) Unit of E. Merck Pharmaceuticals. There is a comprehensive leaflet on the prescription of L-tryptophan from this organisation with appropriate addresses, telephone numbers and so forth. There is also an excellent patient information leaflet which should accompany the prescription. Confidentiality of patients will be maintained by only giving the patient's initials and date of birth to this agency. The preparation is limited to its use in patients with treatment resistant lllness and this is defined as "patients who have had severe and disabling depressive illness continuously for more than two years." The drug is to be used by hospital specialists only and as an adjunct to other drug treatments after an adequate trial of standard antidepressants has been made. It is also important to note that L-tryptophan should not be given with a selective serotonin re-uptake inhibitor (SSRI). Patients receiving $L$-tryptophan should be kept under survellance which should include the monitoring of eosinophil levels as well as questioning for muscle symptomatology. Other measures concerning the purity of the product and its stability rest with the company.

Even given these reasonable restrictions, it is with some relief that we see the product's continued avallability. The phenomenon found previously (Ferrier et al, 1990) of rapid relapse on cessation of L-tryptophan will cease to be a problem. I would suggest that discontinuation of the drug when a patient has been felt to be sufficiently stable for a long enough period should, as with many other psychopharmacological products, be gradual.

\section{References}

ECCLESTON. D. (1993) L-Tryptophan and depressive Illness: a valuable adjunct to therapy? Psychiatric Bulletin. 17, 223-224.

FERRIER, I.N., ECCleston, D., MOORE, B.M. et al (1990) Relapse of chronic depressives on withdrawal of L-tryptophan. Lancet, 336, 380-381

Donald Eccleston, Professor of Psychiatry, Royal Victorla Infirmary, Newcastle upon Tyne, NE1 4LP 